\title{
MicroscopyPioneers
}

\section{Pioneers in Optics: Michael Faraday}

\section{Eric Clark}

From the website Molecular Expressions created by the late Michael Davidson and now maintained by Eric Clark, National Magnetic Field Laboratory, Florida State University, Tallahassee, FL 32306

eclark@magnet.fsu.edu

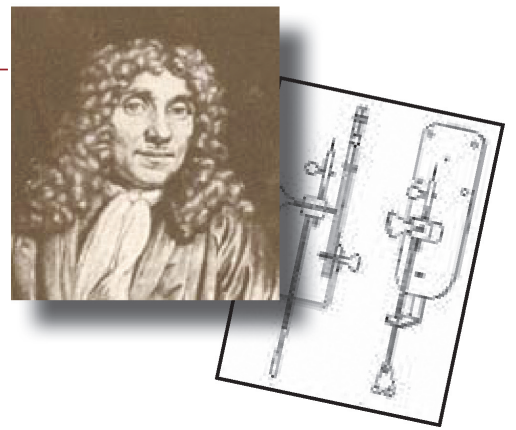

\section{Michael Faraday}

(1791-1867)

When Michael Faraday was born to a blacksmith in Surrey, England, on September 22, 1791, there was little expectation that he would become one of the most influential scientists of the nineteenth century. His parents had nine other children, and money tended to be scarce. They could not afford to provide a formal education for Faraday, but instead depended on a Sunday school to bestow the rudiments of reading, writing, and arithmetic on him. His family moved

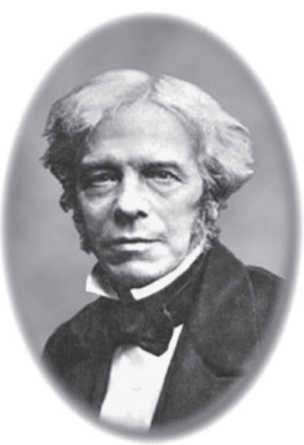
to the city of London in his youth, and there his life took an unexpected turn when he was apprenticed to a bookbinder. The position placed Faraday in close proximity to an endless array of books, and his love of reading was ignited and fueled. He was particularly interested in texts regarding electricity, chemistry, and magnetism, which would eventually become the areas of inquiry that dominated his life.

In 1812, Faraday had the opportunity to attend the public lectures of Humphry Davy, an influential chemist, at the Royal Institution of London. An attentive listener, Faraday took hundreds of pages of detailed notes and used them to try to break into the world of science. Having bound them in leather, he sent them to Sir Joseph Banks, the president of the Royal Society of London. He never received a response from Banks, so he sent a copy to Davy along with an application for work. Although Davy had no openings at the time, he remembered Faraday when he fired his assistant in 1813. Faraday's early tasks were menial, but he learned a vast amount of information, especially in the field of chemistry, from Davy over the years and would eventually establish his own scientific career.

Another scientist's discovery was the inspiration for Faraday's earliest notable scientific contribution. In 1820, Danish physicist Hans Christian Oersted was surprised to find that electric current could be converted into a magnetic force. Faraday believed that the reverse must also be true and set out to create electricity from magnetism. Although he would continue to work on the issue for many years to come, in only a matter of months he had built the first electric motor. The device basically consisted of a magnet, a chemical battery, and a hinged wire. When the current was turned on, the wire would begin to spin around the magnet. At the time, the device was considered more of a novelty than anything else, but its construction was the cause of a significant amount of jealousy in Davy, who claimed that the idea on which it was based was his own.

Faraday was now on the road to establishing himself as a great mind of the day. In 1823, he produced laboratory temperatures below the freezing level, which would eventually spawn the field of cryogenics, and then less than two years later he discovered the compound benzene. He was elected into the Royal Society in 1824 , the only dissenting vote coming from Davy, and was made head of the laboratory at the Royal Institution in 1825. Though Faraday developed a reputation as an excellent lecturer, experimentation remained his primary interest, and he diligently continued his efforts.

Having first invented the transformer, Faraday made his most famous scientific contribution when he established the principle of electromagnetic induction in 1831 to explain his experimental findings. Then, desiring to create a continuous electric current rather than a momentary surge, Faraday invented the dynamo, in the form of a copper disk rotating between the poles of a permanent magnet. Extremely productive in this period of his life, by 1832 Faraday had also established the laws of electrolysis that bear his name. Numerous hours of hard work and mental strain eventually had an adverse effect on him, and he suffered a nervous breakdown in 1839 .

Faraday's health was not improved enough for him to return to active research until 1845. At that time, he began studying the influence of magnetic fields on plane-polarized light waves and discovered that the plane of vibration is rotated when the light path and the direction of the applied magnetic field are parallel, a phenomenon now known as the Faraday effect. His findings regarding light and magnetism strengthened his belief in what he described as the unity of the forces of nature, by which he meant that all forces are manifestations of a single universal force and, therefore, should be convertible into one another. In his attempts to prove that all matter reacts to a magnetic force, he established the classes of materials known as paramagnetic and diamagnetic and ultimately revolutionized contemporary notions of space and force.

His work would prove extremely influential, but Faraday's health was once again in decline by 1855 , and he battled bouts of senility for the rest of his life. Queen Victoria recognized his significant contributions by offering him a home in Hampton Court and the honor of knighthood. Though he accepted the use of the cottage, Faraday declined to be knighted, preferring to simply remain "Mr. Faraday." The modest man who reached great heights died on August 25, 1867, in London, England. 
From Eye to Insight

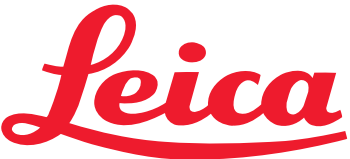

M I C R O S Y S TEM S

2SYSTEMS IN 1 for visual \& chemical analysis

SECOND to a chemical fingerprint

OSAMPLE PREPARATION

DONE:
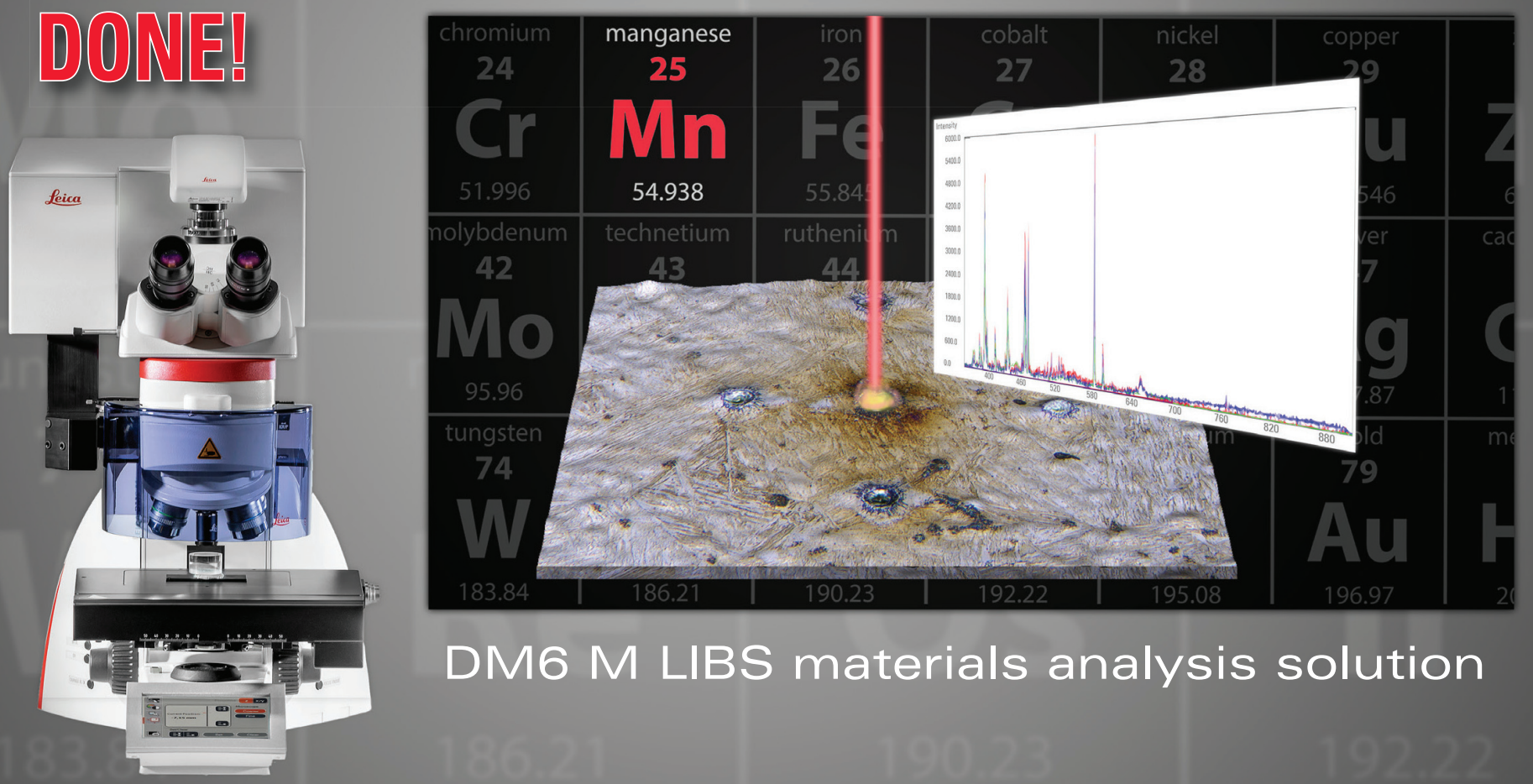

DM6 M LIBS materials analysis solution

\section{VISUAL AND CHEMICAL INSPECTION \\ IN ONE STEP SAVES 90\% OF YOUR TIME}

Visually inspect and chemically analyze in a single work step with your DM6 M Laser Induced Breakdown Spectroscopy (LIBS) materials analysis solution. The integrated laser spectroscopy function delivers the chemical composition of the microstructure that you see in the microscope image - within seconds.

LEARN MORE TODAY:

www.leica-microsystems.com/MTLIBS

Discover More 